\title{
Financial Literacy and Quantitative Reasoning in the High School and College Classroom
}

Annamaria Lusardi

The George Washington University School of Business, alusardi@gwu.edu

Dorothy Wallace

Dartmouth College, dorothy.wallace@dartmouth.edu

\section{Recommended Citation}

Lusardi, Annamaria, and Dorothy Wallace. "Financial Literacy and Quantitative Reasoning in the High School and College Classroom." Numeracy 6, Iss. 2 (2013): Article 1. DOI: http://dx.doi.org/10.5038/ 1936-4660.6.2.1 


\title{
Financial Literacy and Quantitative Reasoning in the High School and College Classroom
}

\begin{abstract}
This overview frames the eight articles devoted to financial literacy in this issue of Numeracy. The survey questions used to assess financial literacy in the United States, Romania, France, Switzerland, Australia, and elsewhere include mathematics that is routinely covered in mathematics and quantitative reasoning courses. Financial literacy, wherever it is received, appears to benefit people throughout their lives. The close tie between quantitative and financial literacy may be exploited to introduce more of both into the high school and undergraduate curriculum.
\end{abstract}

\section{Keywords}

financial literacy, quantitative reasoning

Creative Commons License

(c) (1) (9)

This work is licensed under a Creative Commons Attribution-Noncommercial 4.0 License

\section{Cover Page Footnote}

Annamaria Lusardi is the Denit Trust Distinguished Scholar and Professor of Economics and Accountancy at the George Washington School of Business and Director of the Global Financial Literacy Excellence Center. Previously, she was the Joel Z. and Susan Hyatt Professor of Economics at Dartmouth College. She has also taught at Princeton University, the University of Chicago Public Policy School, the University of Chicago Booth School of Business, and Columbia Business School. In 2008 she was a visiting scholar at Harvard Business School. She is the recipient of the William E. Odom Visionary Leadership Award from the Jump\$tart Coalition for Personal Financial Literacy and the National Numeracy Network's inaugural 2012 Steen Award.

Dorothy Wallace is a professor of mathematics at Dartmouth. She was 2000 New Hampshire CASE Professor of the Year, and the lead PI of the seminal NSF project, Mathematics Across the Curriculum. She recently finished a text in mathematical biology for first-year students, "Situated Complexity." She was a charter board member of the National Numeracy Network and is now co-editor of this journal. 


\section{Introduction}

Suppose you have $\$ 100$ in a savings account and the interest rate is $2 \%$ per year. After five years, would you have $\$ 102$ in the account? More? Less?

Is this a quantitative reasoning question? Yes. Is it being used to measure quantitative literacy in colleges? Not exactly. This question is one of those being used by the Financial Industry Regulatory Authority (FINRA) National Financial Capability Study (NFCS) to assess the financial literacy of Americans. In a sample of over 28,000 respondents age 18 and up, over $20 \%$ answered this question incorrectly (Lusardi and Mitchell 2011a).

This question is the simplest of three benchmark financial literacy assessment questions designed by Lusardi and Mitchell (2011b) and now used worldwide. This issue of Numeracy features a theme collection of papers discussing findings resulting from the use of these questions to measure the financial literacy of the Swiss (Brown and Graf 2013), the French (Arrondel et al. 2013), the Romanians (Beckmann 2013), and the Australians (Agnew et al. 2013). In these papers you will find comparable research results spanning populations worldwide and telling the same story over and over again. Furthermore, you will read about financial literacy in the United States (Bumcrot et al. 2013; Allgood and Walstad 2013; Mottola 2013; de Bassa Scheresberg 2013): about which states' populations know the most and which know the least, which population subgroups display the lowest financial literacy, and how financial literacy is linked to financial behavior-from planning for retirement to holding precautionary savings to borrowing using credit cards and other methods. Taken together, the research presented in this theme collection provides solid evidence of the need for quantitative reasoning skills for all people, the importance of emphasizing practical quantitative reasoning in the curriculum, and the economic and personal consequences for failing to do so.

\section{Financial Literacy Depends on Quantitative Literacy}

Survey questions such as the financial literacy questions examined in the research documented in the theme collection are overtly mathematical tests of the understanding of interest rates and interest compounding. These are routine subjects of mathematics and quantitative reasoning courses. To students without an understanding of the role that interest compounding plays in building wealth, it is impossible to explain why making a high-return investment is better than using a low-interest savings account. To students without an understanding of the actual mathematics underlying interest compounding, it is very difficult to explain the importance of starting to save early or how quickly debt grows when borrowing at the interest rates charged by credit card companies or by payday lenders or other purveyors of high-cost methods of borrowing, topics covered in three of the papers discussing the NFCS data in the theme collection.

Is it better to use your money to buy a single stock or to invest in a fund containing many different stocks? The second strategy is designed to reduce the risk of having that one stock suddenly plunge in value. Despite the age-old adage recommending not putting all of one's eggs in a single basket, most survey respondents do not, in fact, grasp the concept of risk diversification. It is, however, possible to use quantitative reasoning to 
arrive at a good answer to the question of choosing a single stock versus a stock mutual fund. A good answer could be based on the analysis of publicly available growth records of stocks versus funds, generally expressed graphically. The ability to read and interpret graphs is fundamental to quantitative literacy. A more complex approach could involve spreadsheets simulating multiple stocks and a Monte Carlo algorithm of some sort. In either case, understanding why the "correct" answer is a good one demands quantitative reasoning on some level.

\section{Financial Literacy Is Correlated with Good Financial Practices}

It is astoundingly hard to demonstrate that any particular educational intervention will have consequences for the well-being of learners throughout their entire lives. The theme collection provides multiple studies demonstrating that an understanding of these few mathematical and financial principles is significantly correlated with good financial behaviors. In short, financial literacy is a case in which education (wherever it was received) is likely to bring benefits in the short, medium, and long run to those who have it. People are more likely to plan for retirement, to avoid longstanding credit card bills, late payments, payday loans, and other risky financial behaviors if they understand some basic mathematical principles underlying financial literacy. The NFCS data, as discussed in four of the eight papers, provides an opportunity to do an unprecedented analysis of both financial literacy and its links to financial behavior. As more and more individuals become responsible for contributing to their retirement funds and then judiciously managing them after retirement, the need for basic financial understanding among the entire population is increased dramatically. And as young people take up larger amounts of debt to finance their education, it seems essential that they understand the basics of interest compounding. The president of your college or university should care about this matter, as it affects nearly every student. The most promising career, for which the college may meticulously have prepared a student, can be ruined by bad financial decisions, made perhaps not of necessity but of ignorance.

\section{Financial Literacy Is Low among the Young}

Not just in the United States but in other countries as well, the young display low levels of financial literacy and are often the subgroup with the lowest level of financial literacy. These are people who will be paying off student loans, who will be buying their first car to get to work, who will be buying their first home. More and more, young people's earliest financial decisions are related to debt, and it is worrisome to see that in the United States, 35\% of young adults (age 25-34) have used high-cost methods of borrowing such as payday loans, pawn shops, tax refunds loans, auto title loans, and rent to own shops (de Bassa Scheresberg 2013). When looking at both financial literacy and financial behavior, the young emerge as one of the most vulnerable groups in the population. Many of these young adults are the people we have taught in our two- and four-year institutions of higher education. Taken collectively, the papers in this theme collection may lead you to the conclusion that it is irresponsible not to require financial 
literacy of students and that, furthermore, such a requirement must have an explicit, heavily emphasized, practical quantitative component.

\section{Financial Literacy Is Low among Women}

The financial literacy papers discuss data that indicate a large gender gap in financial literacy. Women are not only less likely to answer financial literacy questions correctly; they are also more likely to state they "do not know" the answer to the questions. The pattern is remarkably similar in countries as different as the United States, Australia, France, and Romania. As the findings from the paper discussing financial literacy in Switzerland (Brown and Graf 2013) show, this disparity in literacy level does not seem to be driven by lack of interest in financial matters. Gender differences exist not only in financial literacy but also in financial behavior, and they are the particular focus of one of the papers (Mottola 2013). As teachers of quantitative and financial literacy, we have to remember that there are differences in our student population and that women and men are very different when dealing with the concepts underlying financial knowledge. These findings also call for programs targeted specifically to women.

\section{Money Is Power; Money Is Number}

We live in a capitalist democracy. Functionally, this means that citizens have two sources of power: their vote and their dollar. The design team of Mathematics and Democracy (National Council on Education and the Disciplines 2001) framed quantitative literacy as a skill required for full participation in citizenship, and this participation requires more decisions about money now than ever before. A citizen who cannot manage his or her finances, who lives from hand to mouth, and who arrives destitute at retirement age expecting a long, comfortable, and healthy old age on Social Security payments has surrendered most of his or her power over life in the short, medium, and long run. Put enough such citizens together and you have a national crisis. It is notable that the Organisation for Economic Co-operation and Development's (OECD) Programme for International Student Assessment (PISA) has added financial literacy to the topics it evaluates every three years among 15-year-old students. PISA explains what it measures as follows:

Are students well prepared for future challenges? Can they analyze, reason, and communicate effectively? Do they have the capacity to continue learning throughout life? The OECD Program for International Student Assessment (PISA) answers these questions and more through its surveys of 15-year-olds in the principal industrialized countries. Every three years, it assesses how far students near the end of compulsory education have progressed in acquiring some of the knowledge and skills essential for full participation in society. ${ }^{1}$

Thus, financial literacy has been recognized as a necessary skill to successfully navigate today's society. It is time to add it not only to high school curricula but also to colleges both across the nation and around the world.

\footnotetext{
${ }^{1}$ See http://www.oecd.org/pisa/.
} 


\section{What Colleges and Universities Can Do}

Colleges and universities are beginning to recognize the need for both financial and quantitative skills. In a preliminary study of a random sample of four-year undergraduate institutions, we find that $65 \%$ offer either a quantitative reasoning or personal finance course. These provide some leverage for the kind of education that leads to financial literacy. Many quantitative reasoning courses may not have sufficient emphasis on financial topics in a practical context. Many personal finance courses may not have sufficient emphasis on the quantitative aspects of financial decisions that lead to real, actionable understanding. Many of the courses we found are not actually required. But their presence in the curriculum reflects an understanding of the need they fill for students and provides a basis for further growth. ${ }^{2}$

Textbooks designed for personal finance courses often do not emphasize the mathematical understanding needed to make thoughtful financial decisions and plans. Texts meant for quantitative reasoning courses may give only modest attention to financial decisions. Such texts may be supplemented by more in-depth modules such as those created by the Dartmouth College Financial Literacy Initiative, available on the Internet. ${ }^{3}$ In short, the resources are available to promote financial literacy through the education we provide to our college-level students. Those who teach quantitative reasoning would do well to remember that, as Lynn Steen once wrote, numeracy is about "applying elementary tools in sophisticated settings" (Steen 2001, p. 108). Financial literacy presents a spectacular collection of sophisticated settings useful for improving both financial and quantitative reasoning.

\section{References}

Agnew, J. R., H. Bateman, and S. Tharp. 2013. Financial literacy and retirement planning in Australia. Numeracy 6(2). http://dx.doi.org/10.5038/1936-4660.6.2.7

Allgood, S. and W. Walstad. 2013. Financial literacy and credit card behaviors: A crosssectional analysis by age. Numeracy 6(2). http://dx.doi.org/10.5038/1936-4660.6.2.3

Arrondel, L., M. Debbich, and F. Savignac. 2013. Financial literacy and financial planning in France. Numeracy 6(2). http://dx.doi.org/10.5038/1936-4660.6.2.8

Beckmann, E. 2013. Financial literacy and household savings in Romania. Numeracy 6(2). http://dx.doi.org/10.5038/1936-4660.6.2.9

Brown. M. and R. Graf. 2013. Financial literacy and retirement planning in Switzerland. Numeracy 6(2). http://dx.doi.org/10.5038/1936-4660.6.2.6

Bumcrot, C, J. Lin, and A. Lusardi. 2013. The geography of financial literacy. Numeracy 6(2). http://dx.doi.org/10.5038/1936-4660.6.2.2

de Bassa Scheresberg, C. 2013. Financial literacy and financial behavior among young adults: Evidence and implications. Numeracy 6(2). http://dx.doi.org/10.5038/1936$\underline{4660.6 .2 .5}$

\footnotetext{
${ }^{2}$ Lusardi taught a graduate course on this topic at the George Washington School of Business. A syllabus is available upon request.

${ }^{3}$ Dartmouth College Financial Literacy Initiative curriculum materials at http://www.math.dartmouth.edu/ mqed/FinancialLiteracyProject/
} 
National Council on Education and the Disciplines. 2001. Mathematics and democracy: The case for quantitative literacy, ed. L. A. Steen. Princeton, NJ: Woodrow Wilson National Fellowship Foundation.

Lusardi, A., and O. S. Mitchell. 2011a. Financial literacy and retirement planning in the United States. Journal of Pension Economics and Finance 10(4): 509-525. http://dx.doi.org/10.1017/S147474721100045X

Lusardi, A., and O. S. Mitchell. 2011b. Financial literacy and planning: Implications for retirement wellbeing. In Financial literacy: Implications for retirement security and the financial marketplace, ed. O. S. Mitchell and A. Lusardi, 17-39. Oxford, UK: Oxford University Press.

http://dx.doi.org/10.1093/acprof:oso/9780199696819.003.0002

Mottola, G. R. 2013. In our best interest: Women, financial literacy, and credit card behavior. Numeracy 6(2). http://dx.doi.org/10.5038/1936-4660.6.2.4

Steen, L. A. 2001. Embracing numeracy, in Mathematics and democracy: The case for quantitative literacy, ed. L. A. Steen, 107-116. Princeton, NJ: National Council on Education and the Disciplines. 